\title{
Review \\ UBL5/Hub1: An Atypical Ubiquitin-Like Protein with a Typical Role as a Stress-Responsive Regulator
}

\author{
Sittinan Chanarat
}

Citation: Chanarat, S. UBL5/Hub1 An Atypical Ubiquitin-Like Protein with a Typical Role as a Stress-Responsive Regulator. Int. J. Mol. Sci. 2021, 22, 9384. https:// doi.org/10.3390/ijms22179384

Academic Editor: Atsushi Matsuzawa

Received: 13 August 2021

Accepted: 29 August 2021

Published: 30 August 2021

Publisher's Note: MDPI stays neutral with regard to jurisdictional claims in published maps and institutional affiliations.

Copyright: (c) 2021 by the author Licensee MDPI, Basel, Switzerland. This article is an open access article distributed under the terms and conditions of the Creative Commons Attribution (CC BY) license (https:/ / creativecommons.org/licenses/by/ $4.0 /)$.
Laboratory of Molecular Cell Biology, Department of Biochemistry and Center for Excellence in Protein and Enzyme Technology, Faculty of Science, Mahidol University, Bangkok 10400, Thailand; sittinan.cha@mahidol.edu
Abstract: Members of the ubiquitin-like protein family are known for their ability to modify substrates by covalent conjugation. The highly conserved ubiquitin relative UBL5/Hub1, however, is atypical because it lacks a carboxy-terminal di-glycine motif required for conjugation, and the whole E1-E2-E3 enzyme cascade is likely absent. Though the conjugation-mediated role of UBL5/Hub1 is controversial, it undoubtedly functions by interacting non-covalently with its partners. Several interactors of UBL5/Hub1 identified to date have suggested broad stress-responsive functions of the protein, for example, stress-induced control of pre-mRNA splicing, Fanconi anemia pathway of DNA damage repair, and mitochondrial unfolded protein response. While having an atypical mode of function, UBL5/Hub1 is still a stress protein that regulates feedback to various stimuli in a similar manner to other ubiquitin-like proteins. In this review, I discuss recent progress in understanding the functions of UBL5/Hub1 and the fundamental questions which remain to be answered.

Keywords: ubiquitin-like protein; UBL5/Hub1; pre-mRNA splicing; Fanconi anemia pathway; mitochondrial unfolded protein response; stress-responsive regulations

\section{Introduction}

Post-translational modification is important for cell growth and stress response. In general, proteins are modified by several types of biochemical reactions, for example, phosphorylation, methylation, acetylation, and ubiquitination. Among them, ubiquitination is unique, because it involves a conjugation of ubiquitin, a 76-amino-acid polypeptide, to other proteins through a reversible isopeptide bond formed between the carboxy (C)terminal glycine of the ubiquitin and the $\varepsilon$-amino group of lysine or methionine residue of the targets $[1,2]$. The consequences of ubiquitination depends on whether the ubiquitin is linked to the protein as a monomer or as chains of polyubiquitin [1-3]. Particularly, ubiquitin is known for its role in the proteasome-dependent proteolytic pathway, the pathway that degrades the majority of diverse intracellular proteins [1,3]. A vast number of other pathways are also regulated by ubiquitination; such a modification is, thus, crucial for all-molecular, cellular, and organismic-levels of biology [1-3].

It has emerged that all eukaryotes express proteins that are related in sequence to ubiquitin and function in an analogous manner. Collectively called ubiquitin-like (UBL) proteins, they play versatile roles in normal and disease-related cellular processes; for example, SUMO regulates transcription, chromatin structure, and DNA repair, RUB1/NEDD8 is implicated in cell cycle control and various cellular pathways, and ATG8 functions in autophagy $[1,2,4]$. All UBL proteins share a globular $\beta$-grasp fold structure composed of a curved $\beta$-sheet wrapping around a central $\alpha$-helix $[4,5]$. Canonical members of the UBL family contain a di-glycine (di-Gly) motif at their C-terminus for target conjugation and share a capability of being conjugated to target molecules through an ATP-dependent E1-E2E3 enzymatic cascade, thereby functioning as covalent protein modifiers (Figure 1A,B) [5]. The covalent modification by members of the UBL family alters activities of the substrate by influencing its stability, localization, or behavior of molecular interaction. Depending on 
the targets, UBL conjugation affects a number of metabolic pathways, for example, DNA damage repair, signal transduction, protein sorting, cellular differentiation, and organ development $[4,5]$.

A

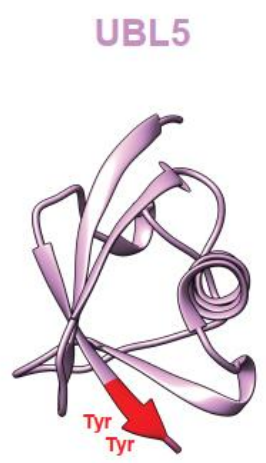

B

UBL5

Nedd8

Ubiquitin

ISG15

FAT10

UFM1

SUMO3

SUMO2

SUMO1

consensus

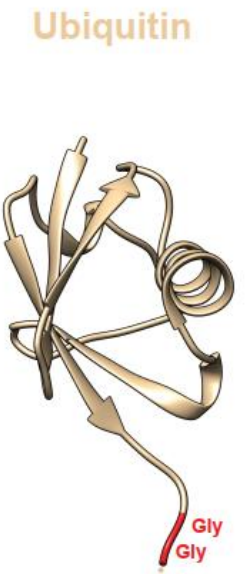

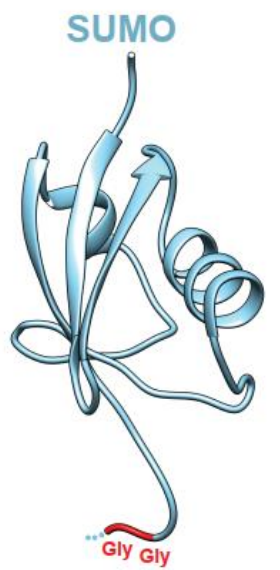

NEDD8

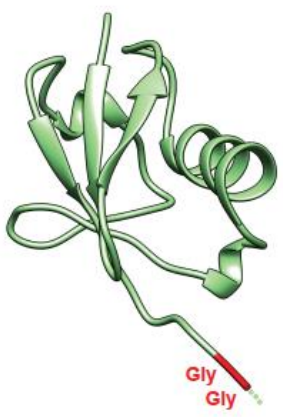

\section{C}

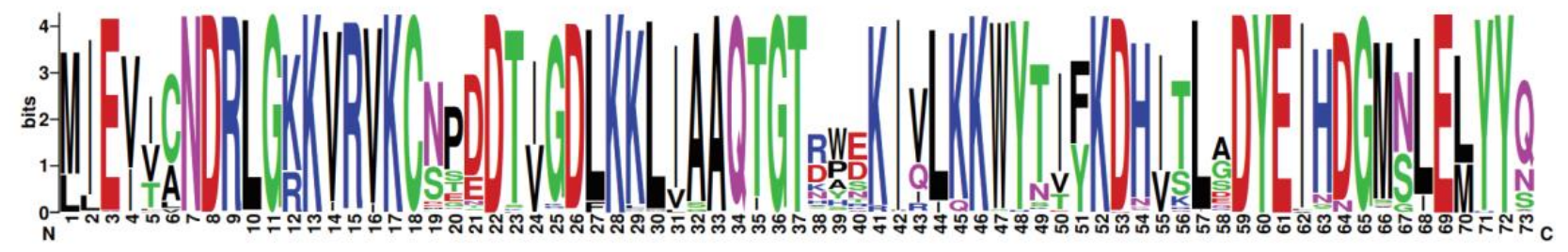

Figure 1. Three-dimensional structures and protein sequences of UBL5/Hub1 and other members of the ubiquitin family. (A) Structural ribbon representation of UBL5/Hub1 (PDB: 4PYU), ubiquitin (PDB: 1UBQ), SUMO-3 (PDB: 1U4A), and NEDD8 (PDB: 2N7K). C-terminal di-tyrosine motif of UBL5/Hub1 and di-glycine residues of others are highlighted in red. (B) Sequence alignment of human UBL5/Hub1 with ubiquitin and other ubiquitin-like proteins. The scissor symbol shows the processing site after the C-terminal di-glycine motif. The di-tyrosine motif of UBL5/Hub1 is underlined. (C) Weblogo [6] representation of the top 250 homologs identified by Blastp search using human UBL5 as query sequence [7]. The $y$-axis represents the bit score. Note that UBL5/Hub1 proteins in certain species carry a few amino acids that are extended from the N-terminus of the core ubiquitin-like domain; therefore, the sequence conservation at the first position is less than the maximum entropy of $\log _{2} 20$ (4.32) bits [6].

While the main focus of UBL studies is on canonical members of the family, relatively little is known about functions of UBL proteins which do not covalently modify their target proteins. Here, I review an atypical member of the UBL family, namely UBL5/Hub1, and discuss its molecular functions and future perspectives.

\section{UBL5/Hub1}

Ubiquitin-like protein 5 (UBL5), also known in yeast Saccharomyces cerevisiae as homologous to ubiquitin 1 (Hub1), is an evolutionarily conserved 73-amino-acid protein in the UBL family [8-11]. Similar to ubiquitin and other relatives, UBL5/Hub1 adopts the 
ubiquitin-like $\beta$-grasp fold, the fold that consists of a five-strand antiparallel $\beta$-sheet surrounding an $\alpha$-helix (Figure 1A). Solution and crystal structures reveal that the secondary structure elements of UBL5/Hub1 are $\beta-\beta-\alpha-\beta-\beta-3_{10}-\beta$ along the protein sequence [9-12]. According to a Dali search of the Protein Data Bank (PDB), the structure most similar to UBL5/Hub1 among members of the UBL family is ubiquitin, although they share only $22 \%$ sequence identity (Figure 1B) [12]. However, unlike ubiquitin, the electrostatic surface of UBL5/Hub1 is highly charged and the protein contains no large hydrophobic patches [9-12]. From this aspect, UBL5/Hub1 might be a divergent member of UBL family; its structural similarity to ubiquitin may merely reflect a shared folding topology.

Major differences between UBL5/Hub1 and other UBL proteins are at the C-terminus. Typically, most members of the family possess the di-Gly motif, which is processed to achieve the mature form prior to covalent conjugation to protein targets. UBL5/Hub1, however, contains a conserved di-tyrosine (di-Tyr) motif followed by an unconserved amino acid at its C-terminal end (Figure 1A-C). Additionally, UBL5/Hub1 is shorter than the others, as it completely lacks an exposed characteristic C-terminal tail of UBL proteins [8-12].

\section{To Be (Conjugated), or Not to Be, That Is the Question}

As C-terminal tail and di-Gly motif are often required for UBL conjugation, it is controversial whether UBL5/Hub1, which lacks these features, is capable of canonical covalent modification.

Broadly speaking, UBL proteins fall into two separate categories. Proteins of the first category function as covalent modifiers in a manner analogous to ubiquitin $[4,5]$. They are processed by specific enzymes and then covalently attached to target molecules via their C-termini. These proteins are often termed "ubiquitin-like modifiers", or ULMs. On the other hand, proteins of the second category, called "ubiquitin-domain proteins", or UDPs, bear one or more domains resembling ubiquitin in primary sequence and tertiary structure $[4,8,13,14]$. Unlike ULMs, UDPs are not conjugated to other molecules and function merely by forming protein complexes or binding to their interactors. Often in the form of modular domain proteins, UDPs are widely encoded in eukaryotic genomes and function in many cellular pathways: Rad23, ubiquilin, and Parkin play roles in proteasome-mediated protein degradation; homocysteine-induced ER protein (Herp) functions in endoplasmic reticulum-associated protein degradation; oligoadenylate synthase-like (OASL), a unique two-UBL-domain protein, is implicated in antiviral activity $[13,14]$.

Originally, a group of scientists proposed in an in vivo study in Saccharomyces cerevisiae that UBL5/Hub1 may be a ULM, which is able to be attached to protein targets [15]. In yeast, Hub1 is 73-amino-acid long and contains a di-Tyr motif followed by a leucine residue (Leu73) at its C-terminus. In a western blot analysis of Hub1-immunoprecipitation, Hub1 wild-type does not show any conjugates [15]. However, a mutant variant lacking the Leu73 strongly forms multiple high-molecular-mass species of Hub1-protein adducts, and removal of the last two residues, Tyr72 and Leu73, completely abolishes the complex. Based on these results, the di-Tyr motif is required for modifying protein targets and Hub1 must be post-translationally processed by the removal of Leu73 [15]. Nevertheless, it has not been confirmed whether Hub1 is conjugated to its target via a covalent bond; additionally, Hub1 processing protease as well as Hub1-specific E1-E2-E3 enzyme cascade, if any, are yet to be identified.

Contradictory to the above ULM hypothesis, in vivo and in vitro studies performed by two independent laboratories suggest that UBL5/Hub1 may not be a ULM [8]. Conventionally, UBL proteins are synthesized as inactive precursors and require an initial processing step to expose a $\mathrm{C}$-terminal glycine in the mature modifiers. Specific proteases, for example, deubiquitinating enzymes (DUBs) or UBL-specific proteases (ULPs), are responsible for processing [1-3]. Moreover, an ATP-driven E1-E2-E3 enzymatic cascade activates each modifier prior to target conjugation [2]. The norm, however, may not apply to Hub1. Typically, conjugation of ubiquitin and ULMs is sensitive to the thiol-reactive agent 
$\mathrm{N}$-ethylmaleimide (NEM), an inhibitor of DUBs and proteins with active site cysteines, including E1, E2, and E3 enzymes [16]. Experimental evidence shows that not only does NEM fail to inhibit the formation of SDS-resistant high-molecular-weight protein adducts of Hub1, but the drug also even induces elevation of such adducts [8]. Moreover, unlike the mechanisms of other UBL conjugations, Hub1-protein adducts are ATP-independent and insensitive to either EDTA or apyrase [8]. The C-terminal di-Tyr of Hub1 does not seem to be required, as the removal or mutation of the dipeptide does not affect Hub1-adduct formation [8,17]. Notably, an intact C-terminally tagged Hub1 still forms the adducts, suggesting that C-terminal processing of Hub1 is not required for Hub1-protein complex formation [8]. If this is the case, the observed Hub1-containing SDS-resistant adducts are most likely generated by a mechanism dissimilar to the conjugation of ubiquitin and ULMs (Table 1).

Table 1. Characteristics of adduct formation/target conjugation with UBL5/Hub1 and other members of ubiquitin-like protein family.

\begin{tabular}{cccccc}
\hline & \multicolumn{4}{c}{ Requirement for Adduct Formation/Target Conjugation } & NEM a Sensitivity of Adduct \\
\cline { 2 - 6 } & E1-E2-E3 Enzymes & C-Terminal Glycine & $\begin{array}{c}\text { Processing of the } \\
\text { C-Terminal Tail }\end{array}$ & ATP & Formation/Conjugation \\
\hline UBL5/Hub1 & No & No & No & No & No \\
\hline $\begin{array}{c}\text { Ubiquitin and } \\
\text { ubiquitin-like } \\
\text { modifiers }\end{array}$ & Yes & Yes & Yes & Yes & Yes \\
\hline
\end{tabular}

a NEM: N-ethylmaleimide.

Whether UBL5/Hub1 is a ULM or a UDP, the protein is nevertheless a unique member of the UBL protein family. As a ULM, UBL5/Hub1 is conjugated to targets via di-Tyr instead of typical di-Gly motif; as a UDP, UBL5/Hub1 is the only gene identified to date that encodes only a single UBL domain without any additional module and is most likely the smallest protein of this class $[13,14,18]$.

\section{Molecular Functions of UBL5/Hub1}

While its mode of function as a UBL protein is debatable, several lines of evidence support UDP functions of UBL5/Hub1, which regulates certain cellular pathways via interactions with its binding partners. Major molecular findings on the functions of UBL5/Hub1 in pre-mRNA splicing, the Fanconi anemia pathway, and the mitochondrial unfolded protein response are discussed below.

\subsection{Pre-mRNA Splicing}

Splicing is a fundamental step of RNA processing, involving the removal of intronic sequence in precursor messenger RNA (pre-mRNA) $[19,20]$. Accurate pre-mRNA splicing is absolutely required for correct gene expression since any error-even at a single-nucleotide resolution-potentially causes aberrant protein products, thereby ultimately resulting in cellular dysfunction and cell death [19-22]. The reaction of pre-mRNA splicing occurs in the spliceosome, a megadalton ribonucleoprotein complex composed of five small nuclear ribonucleoproteins (snRNPs) and a large number of non-snRNP splicing factors $[19,20]$. To form a catalytically active spliceosome, snRNPs and non-snRNP-associated factors are sequentially and co-transcriptionally recruited de novo to every single intron of the pre-mRNA. First, the $5^{\prime}$-splice site of the intron is recognized by U1 snRNP. U2 snRNP then binds to the intronic branch-site sequence. Next, the pre-assembled U4/U6.U5 tri-snRNP is recruited and forms a pre-catalytic spliceosome. During each step of spliceosome assembly, several RNA helicases help rearrange conformations of proteins and RNA molecules and activate the spliceosome $[23,24]$. Suboptimal introns are rejected and discarded by the 
RNA helicases via kinetic proofreading mechanisms in order to keep splicing fidelity under control [23-26].

UBL5/Hub1 binds to at least two sites of the spliceosome: the U4/U6.U5 tri-snRNPvia an interaction with splicing factors such as Snu66, Prp38, and Spp381, which are yeast homologs of SART1, PRPF38A, and MFAP1, respectively-and the DEAD-box RNA helicase Prp5 (Figure 2A-C) [10,11,27]. SART1/Snu66 and PRPF38A/Prp38 are proteinaceous components of the U4/U6.U5 tri-snRNP. Depending on the species, the Hub1-interaction domain (HIND) motif resides either in the N-terminus of SART1/Snu66 or in the Cterminal end of PRPF38A/Prp38, or in both proteins of some species, such as Plasmodium falciparum [10]. Compared to the interaction between ubiquitin and ubiquitin receptors, UBL5/Hub1 interacts with the HIND motif in a distinct manner. While ubiquitin binds to its receptors mostly via weak hydrophobic interaction, UBL5/Hub1-HIND interaction comprises a strong salt bridge between conserved amino acids, arginine of HIND, and aspartate of UBL5/Hub1, supported by several hydrophobic contacts with high binding affinity $[10,11]$. As demonstrated in yeast, plant, and mammalian studies, the interaction of UBL5/Hub1 with HIND motif is evolutionarily conserved and is important for the function of this ubiquitin relative, indicating its important role in pre-mRNA splicing $[10,11,28]$. Intriguingly, transferring the HIND motif from Snu66 to other components of the U4/U6.U5 tri-snRNP fully restores the function of yeast's Hub1; it is, therefore, believed that the protein serves as a part of the U4/U6.U5 tri-snRNP rather than directly regulating the role of SART1/Snu66 or PRPF38A/Prp38 [10]. Indeed, several structural analyses using single-particle cryo-electron microscopy (cryo-EM) reveal that UBL5/Hub1 resides in different complexes during the process of spliceosome assembly, particularly between pre-catalytic and activated spliceosomal complex formation [29-31]. Besides SART1/Snu66 and PRPF38A/Prp38, UBL5/Hub1 also makes a direct contact with several domains of the core splicing factor PRPF8/Prp8 [30,31]. It is important to note that while UBL5/Hub1 binds to SART1/Snu66 during the pre-catalytic spliceosomal complex (B complex), another B-complex-specific protein MFAP1/Spp381 replaces SART1/Snu66 after the complex is activated by the spliceosomal RNA helicase SNRNP200/Brr2 [30]. In cooperation with MFAP1/Spp381, UBL5/Hub1 likely plays a role in stabilizing the position of 5 -exon and the interaction of U5 snRNA within the pre-catalytic and activated spliceosomal complexes [30]. As UBL5/Hub1, SART1/Snu66, and MFAP1/Spp381 are present in foci in close proximity to-but not entirely overlapped with-the Cajal bodies, which is involved in the assembly and recycling of snRNPs [32-36], it is tempting to speculate that they might contribute to the processes. It is also important to note that MFAP1/Spp381 interacts with UBL5/Hub1 via the HIND-interacting surface in a mutually exclusive manner (Figure 2C) [30]. The mechanism and significance of the substitution is, however, still unknown and yet to be investigated. In any case, UBL5/Hub1 is located at a strategic position within the pre-catalytic and activated spliceosome and helps regulate pre-mRNA splicing.

Another spliceosomal interactor of UBL5/Hub1 is Prp5, an evolutionarily conserved RNA helicase in the DEAD-box protein family [27]. Also known as DDX46, it is involved in bridging U1 and U2 snRNPs during early steps of spliceosome assembly [37]. Prp5 also facilitates the binding of U2 snRNP to branchpoint regions of the intron and functions as a splicing fidelity factor through a kinetic proofreading mechanism $[25,37,38]$. During assembly of the pre-spliceosomal complex, Hub1 binds directly to Prp5 at the invariant aromatic amino acid residue, tryptophan- 257 in yeast. The residue is highly conserved and is in a close proximity to the ATP-binding and hydrolysis site of the helicase [27]. Hub1 interacts with the enzyme via the opposite side of the surface that binds to HIND motif of SART1/Snu66 (Figure 2B) [27]. Acting as an ATPase stimulating co-factor, this ubiquitin relative enhances Prp5's RNA-dependent intrinsic ATPase activity in a dosedependent manner, thereby facilitating overall splicing efficiency [27]. Cellular levels of Hub1 seem to control Prp5 and affect general splicing. When cells are unstressed, the expression level of Hub1 is much less abundant than other spliceosomal components, 
suggesting a minimal activation of Prp5 and the spliceosome by Hub1 under normal conditions [27]. Experimental overexpression of Hub1, however, not only activates Prp5 and the spliceosome, but also affects the selection of splice sites, most likely due to faster splicing kinetics; thereby, the stringency of splicing fidelity becomes more relaxed [27]. More importantly-like many other UBL proteins-UBL5/Hub1 is highly expressed under several stress conditions, for example, hypo-osmotic pressure, oxidative stress, and exposure to heavy metals [10,39-41]. In budding yeast, the stress-induced overexpression of Hub1 is controlled by stress-responsive regulator Yap1 (for yeast-AP1) at the transcriptional level, promotes intron-specific pre-mRNA splicing, and, as a result, helps facilitate tolerance of such stresses (Figure 3A) [39,42].

A

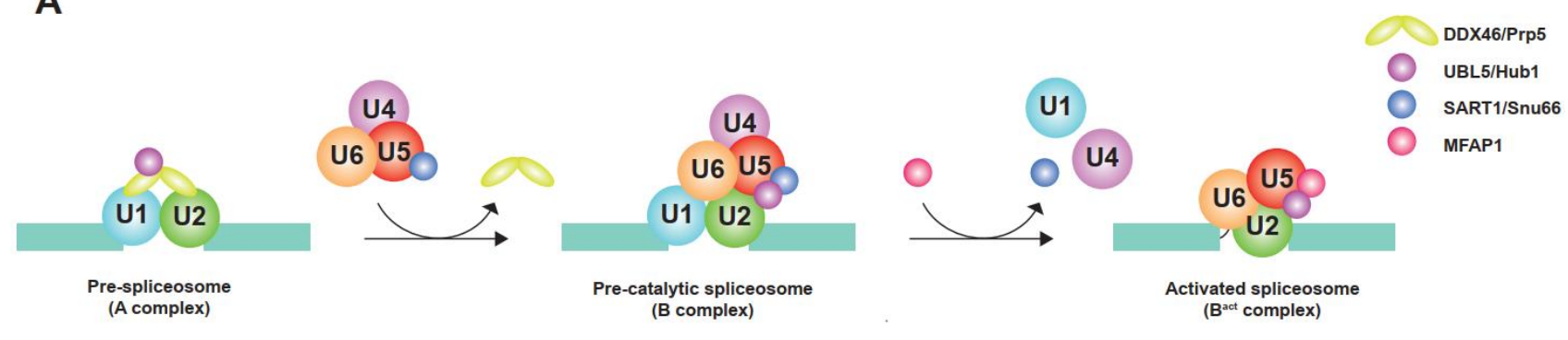

B

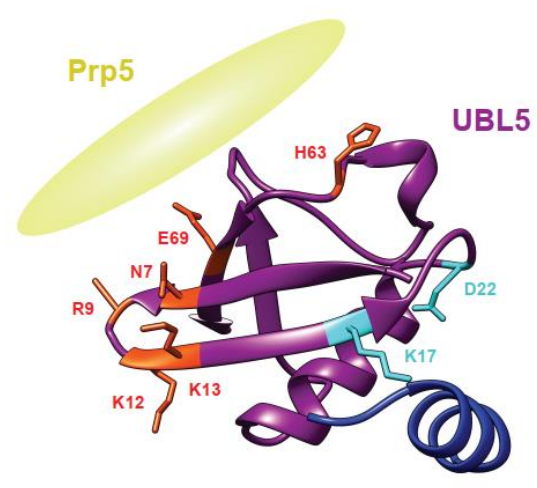

C

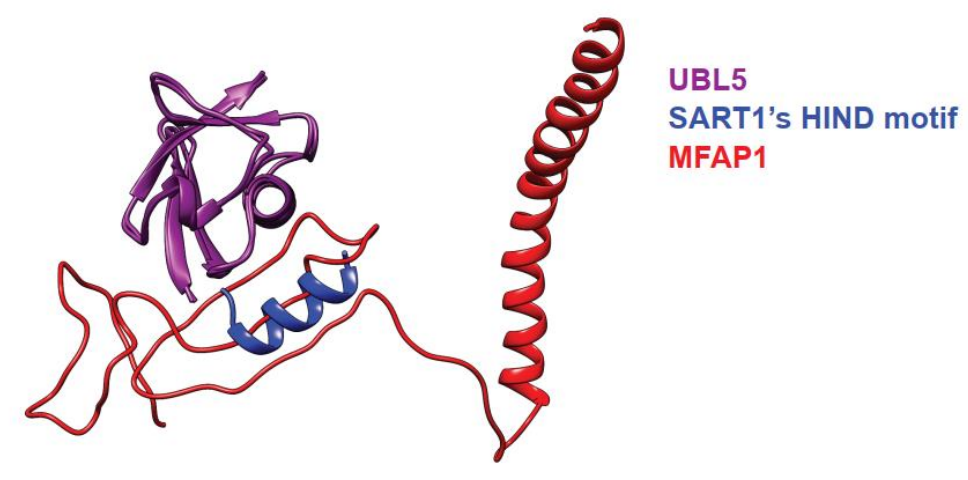

SART1's HIND motif

Figure 2. Sequential and differential interaction of UBL5/Hub1 during assembly and activation of the spliceosome. (A) Schematic depiction of events in which UBL5/Hub1 functions during assembly and activation of the spliceosome. U1 and U2 snRNPs recognize an intron of pre-mRNA and form a pre-spliceosome (A complex). UBL5/Hub1 binds to the RNA helicase DDX46/Prp5 bridging the two snRNPs. After release of the helicase, the ubiquitin relative binds to SART1/Snu66, a component of U4/U6.U5 tri-snRNP that is recruited during the formation of a pre-catalytic spliceosome (B complex). Subsequent recruitment, release, and rearrangement of proteins and snRNAs lead to formation of an activated spliceosome (B ${ }^{\text {act }}$ complex). During the activation, MFAP1/Spp381 replaces SART1/Snu66 and interacts with UBL5/Hub1. (B) Ribbon diagram that shows two functional surfaces of UBL5/Hub1 (purple). Amino acid residues that are important for interaction with DDX46/Prp5 (yellow) and HIND motif of SART1/SNU66 (blue) are labeled in red and light blue, respectively. (C) MFAP1/Spp381 and SART1/Snu66 share the same surface of UBL5/Hub1 for interaction. Superimposition of human UBL5 structures in the pre-catalytic (PDB: 6AHD) and activated (PDB: 7ABG) spliceosomes show the mutually exclusive interaction of MFAP1 (red) and HIND motif of SART1 (blue) with UBL5 (purple).

Hub1-mediated alternative splicing plays physiological roles not only in the stress response but also in the maintenance of integrity of the nuclear envelope in Saccharomyces cerevisiae. In this yeast, Hub1 regulates alternative splicing of SRC1, also called HEH1, which is a gene that encodes an inner nuclear envelope protein [10,43]. Tandem arrangement of overlapping $5^{\prime}$-splice sites in $S R C 1$ pre-mRNA results in two isoforms of mature mRNA and subsequent expression of two protein variants $[10,44]$. The long isoform Src1-L is an 834-amino-acid protein and harbors two transmembrane domains and a winged-helix MSC 
domain (for MAN1-Src1 C-terminal) at its C-terminus. Alternative splicing of the SRC1 pre-mRNA, however, causes a shift in the open reading frame, resulting in an expression of the shorter isoform Src1-S lacking the second transmembrane and the C-terminal MSC domains $[10,43,44]$. While both tandem splice sites of $S R C 1$ pre-mRNA are used in wildtype, cells lacking Hub1 are unable to splice the upstream splice site to produce Src1-S isoform; thereby, only Src1-L isoform is expressed [10]. It has recently been shown that Hub1-mediated splicing generates Src1-S to modulate the recruitment of the endosomal sorting complexes required for transport (ESCRT) machinery to the nuclear envelope, which is critical for the nuclear integrity [43].

A

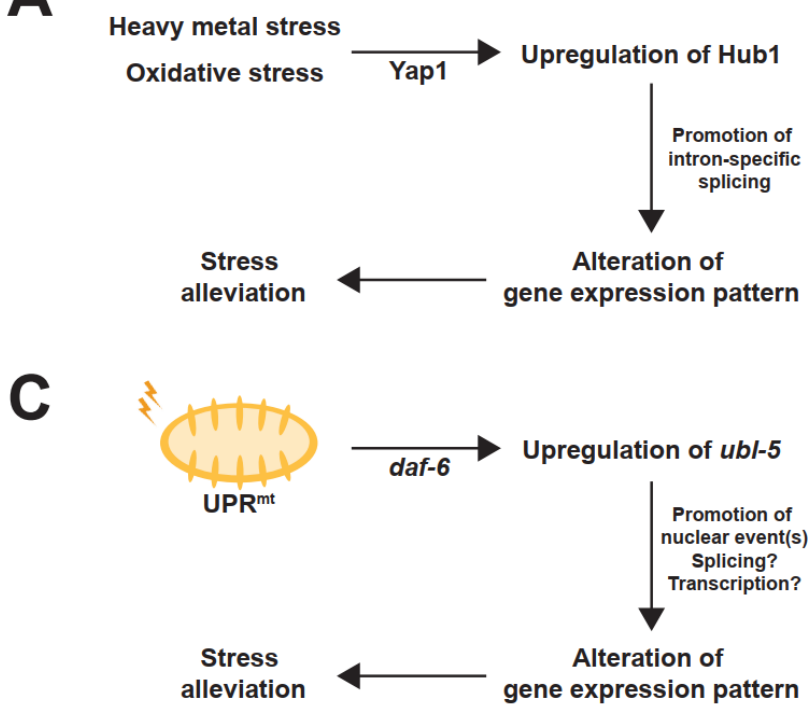

B

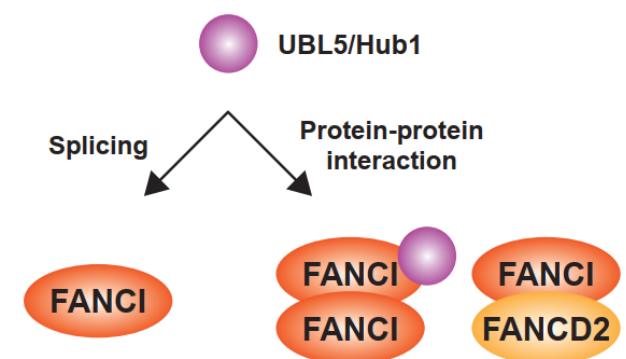

Regulation of FANCI expression

Stabilization of FANCI homodimer \& FAND2-I heterodimer

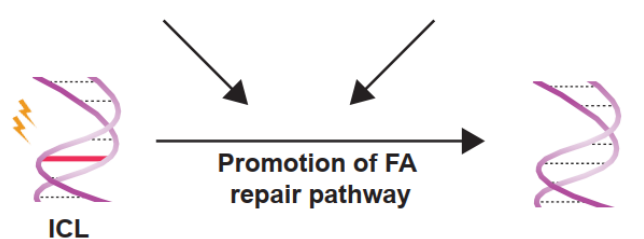

Figure 3. Stress-responsive roles of UBL5/Hub1. (A) In S. cerevisiae, Hub1 is upregulated at the transcriptional level upon heavy metal and oxidative stresses by the yeast-AP1 (YAP1) transcription factor. Overexpressed Hub1 facilitates intron-specific splicing and, as a result, contributes to stress tolerance. (B) As a splicing regulator, UBL5/Hub1 promotes proper splicing of FANCI pre-mRNA. Additionally, this ubiquitin relative interacts with FANCI protein and helps stabilize FANCI homodimer as well as FANCD2-I heterodimer, thereby facilitating the Fanconi anemia (FA) DNA damage repair pathway to resolve interstrand DNA crosslink (ICL). (C) In C. elegans, mitochondrial unfolded protein response (UPR ${ }^{\mathrm{mt}}$ ) induces upregulation of $u b l-5$ which is mediated by the transcription factor daf-16. The gene product is then accumulated and functions in the nucleus, though precise molecular function to alleviate the mitochondrial stress is unclear.

UBL5/Hub1 also plays a splicing-mediated physiological role in humans, i.e., sister chromatid maintenance. Loss of UBL5 causes a global reduction in pre-mRNA splicing efficiency and an increase in intron retention [11,45]. It appears that splicing of not all but specific introns are affected; the phenomenon is similar to Hub1's intron-specific splicing regulation observed in yeasts $[10,17,27,46]$. Particularly in UBL5-deficient cells, the first intron of Sororin, a cohesion protection factor, is retained, while splicing of other introns of the same gene is unaffected [45,47]. The intron retention results in remarkable loss of Sororin protein and a decrease in the load of the protection factor onto chromatin upon mitotic exit [45]. In sum, UBL5 is required for human cells to prevent premature sister chromatid separation by promoting proper pre-mRNA splicing and expression of the cohesion factor Sororin [45].

In higher eukaryotes, UBL5/Hub1 may add another layer of alternative splicing control through its interacting partners, which belong to a class of SR-protein kinases [9,48]. In most eukaryotes, alternative splicing is significantly regulated by a family of serine/argininerich (SR) proteins, which are often phosphorylated by several SR-protein kinases [49-51]. Upon hyper-phosphorylation, SR proteins directly interact with the pre-mRNA and stabilize interactions between spliceosomal components during spliceosome assembly $[49,52,53]$. 
By contrast, de-phosphorylation of SR proteins is required in the late step of splicing for the nuclear export of mature mRNA [54,55]. One family of SR protein-modifying enzymes is the cell division control protein (CDC)-like kinase (CLK), an evolutionarily conserved kinase family that phosphorylates serine, threonine, and tyrosine residues [56,57]. All four isoforms of CLKs are expressed in most cell types and tissues and affect a vast variety of biological processes via splicing control [58]. Notably, yeast two-hybrid screens reveal that UBL5 interacts with all four members of the CLK family $[9,11,48,59]$. Though still elusive, UBL5-CLK interaction may provide an additional layer of SR-protein-mediated regulation of alternative splicing. The hypothesis is yet to be proven.

\subsection{Fanconi Anemia Pathway}

While the roles of UBL5/Hub1 in pre-mRNA splicing are widely established, a line of evidence also suggests that this ubiquitin relative is also involved in the Fanconi anemia (FA) pathway, a DNA damage response mechanism that repairs DNA interstrand crosslinks (ICLs) $[45,60,61]$. ICLs, which are covalent linkages between the opposite strands of double-stranded DNA, can be generated by endogenous metabolites (e.g., aldehydes and nitrous acid) or by exogenous origins (e.g., psoralen or cisplatin used in cancer chemotherapy) $[62,63]$. The FA pathway comprises 19 Fanconi anemia proteins (FANCA to FANCT) and a number of associated proteins. In response to the damage, FANCD2-I heterodimer and FA core complex are recruited to the DNA lesions once the ICLs are detected [63]. In conjunction with E2 conjugating enzyme FANCT, the FA core complex harboring an E3 ubiquitin ligase activity monoubiquitinates and activates FANCD2-I heterodimer, which subsequently coordinates many downstream DNA repair events [47,62-64].

It has been shown in human cells that UBL5 binds to FANCI and promotes the functional integrity of FA pathway. The interaction between these two proteins is constitutive during the $\mathrm{S}$ and $\mathrm{G} 2$ phases of the cell cycle and is independent of UBL5's splicing function and of the monoubiquitination state of the FANCD2-I heterodimer [60]. While existing as a heterodimer with FANCD2, FANCI is additionally able to form FANCD2-independent homodimers and/or oligomers [60]. This higher-order formation of FANCI complex requires UBL5, which stabilizes through a direct protein-protein interaction and protects the complex from proteasome-mediated degradation [60]. While UBL5-FANCI interaction is unaffected by the treatment of mitomycin C-an alkylating agent that induces ICLs-the protein levels of UBL5 is slightly increased upon the drug exposure [60]. Because UBL5 is not accumulated at the damaged DNA and the FA-related role of UBL5 does not require its splicing activity, it is believed that UBL5 stabilizes FANCI and facilitates function of the protein before the recruitment to the ICLs, thereby promoting the FA DNA damage response pathway (Figure 3B) [60].

\subsection{Crosstalk between FA and Pre-mRNA Splicing}

Various lines of evidence show existence of the crosstalk between DNA damage repair and pre-mRNA splicing [64-69]. In particular, it has been shown that proteins in the FA pathway regulate the nuclear dynamics of splicing factors [70]. In situ proximity ligation assay verifies that FANCI and FANCD2 are in close proximity with SF3B1, the largest subunit of U2 snRNP and the most frequently mutated splicing gene in cancers [64,70-72]. In response to ATR activation, FANCI specifically promotes the mobilization of nucleoplasmic pool of SF3B1 from nuclear speckles [70]. Moreover, both FANCI and FANCD2 promote the timely displacement of SF3B1 and certain splicing factors from the chromatin, thereby organizing the nuclear dynamics of splicing factors [70]. Though there is no direct evidence that shows an implication of SF3B1 in FA pathway, it has been reported that components of U2 snRNP are important for the stability of several DNA damage repair proteins [73]. Since UBL5/Hub1 binds to FANCI and U2 snRNP-associated RNA helicase Prp5, it is tempting to speculate that UBL5/Hub1 may play a role in the crosstalk between these two processes/machineries. 


\subsection{Mitochondrial Unfolded Protein Response}

A large number of mitochondrial proteins are encoded in the nuclear genome and must be imported from the cytoplasm into the organelle with the help of molecular chaperones [74]. Several perturbations during mitochondrial protein synthesis and import result in accumulation of unassembled proteins. Upon such a failure, stress responses are rapidly activated to alleviate the proteostasis defects by modulating the environment of protein folding through regulation of the translation and availability of chaperones. In particular, the mitochondrial unfolded protein response (UPR $\left.{ }^{\mathrm{mt}}\right)$ is a stress response system of mitochondria, which selectively activates the transcriptional programs of chaperones and proteases to maintain homeostasis of mitochondrial proteins.

By RNA interference (RNAi) genetic screen in Caenorhabditis elegans, ubl-5 was identified as a candidate factor that plays a role in $\mathrm{UPR}^{\mathrm{mt}}$ [75-77]. Further verification confirms that inactivation of $u b l-5$ is associated with a decrease in expression of C. elegans $\mathrm{UPR}^{\mathrm{mt}}$ genes, $h s p-60$ and $h s p-6$, which encode mitochondrion-specific matrix chaperones $[75,76]$. Expression and activity of $u b l-5$ is likely controlled by the insulin/insulin-like growth factor (IGF) signaling pathway because downregulation of daf-2, a tyrosine kinase homolog of the mammalian insulin/IGF receptor family, induces upregulation of $u b l-5$. Moreover, the ubiquitin relative becomes overexpressed upon mitochondrial stresses at the transcriptional level under the control of stress-induced transcription factor elt-2 and daf-16, whose activity is negatively controlled by daf-2. As a result, $u b l-5$ becomes accumulated in the nucleus and executes the late step in gene expression control of the UPR ${ }^{\mathrm{mt}}$ (Figure 3C) [75,77].

Though the nuclear localization of the ubiquitin relative is consistent with its reported role in pre-mRNA splicing control, it is still unknown whether the protein is implicated in other aspects of gene expression, such as transcription. The precise molecular mechanism of UBL5/Hub1-mediated UPR ${ }^{\mathrm{mt}}$ remains to be elucidated.

\section{Differential Expression of UBL5/Hub1 and Disease Association}

Though the loss of HUB1 gene in budding yeast does not show a growth phenotype under controlled laboratory conditions, mutation of the gene results in growth or development defects and cell lethality in fission yeast, plant, and human $[10,11,17,28]$. Because UBL5/Hub1 plays regulatory roles in several fundamental processes-pre-mRNA splicing, DNA damage repair, and UPR ${ }^{\mathrm{mt}}$ - it is tempting to speculate that malfunction of UBL5/Hub1 may potentially be involved in human diseases. To date, even though diseaseassociated mutation in the protein-coding sequence of UBL5/Hub1 has not been reported, several genetic association studies in mammals suggest that the gene might play a part in energy balance, sleep duration, regulation of fat content, obesity, diabetes, and metabolic disorders [78-84]. Moreover, gene expression analyses of human, mouse, rat, and bovine tissues indicate that UBL5/Hub1 is found in all major tissues and is highly expressed in main glands of the endocrine systems, including hypothalamus, pituitary, thyroid, and adrenal glands [79,85-91]. As high levels of Hub1 are able to modify gene expression patterns by modulating intron-specific pre-mRNA splicing in budding yeast $[27,39,46]$, it is reasonable to assume that differential expression of UBL5 in mammalian tissues may control splicing-mediated expression of genes, some of which may encode hormones and endocrine regulatory factors. The precise mechanism and constitutive/stress-induced involvement of UBL5/Hub1 in the aforementioned metabolic processes and diseases are yet to be studied.

\section{Future Directions}

A growing body of genetic, biochemical, and structural evidence has demonstrated roles of the atypical UBL protein, UBL5/Hub1. A number of questions, however, remain partially or completely unanswered.

(1) If UBL5/Hub1 is indeed a ULM, what are UBL5/Hub1-specific protease(s), E1, E2, and E3 enzymes? How conserved and stress-responsive is the UBL5/Hub1 conjugation pathway? 
(2) What are the precise mechanism and physiological role of UBL5/Hub1-protein adducts?

(3) How does the dynamic protein interaction of UBL5/Hub1 with SART1/Snu66 and MFAP1/Spp381 contribute to spliceosome assembly/activation?

(4) What is a mechanistic explanation for how UBL5/Hub1 stimulates the intrinsic ATPase activity of DDX46/Prp5?

(5) How does co-evolution between UBL5/Hub1 and the spliceosome affect intron variability and genome complexity?

(6) What is the nuclear role of upregulated UBL5/Hub1 in response to UPR ${ }^{\mathrm{mt}}$ ? Is it splicing-mediated regulation or other processes? Is there any crosstalk between different activities of UBL5/Hub1?

(7) What controls the differential levels of constitutively expressed UBL5/Hub1 in a tissue-specific manner? What controls the stress-induced level of UBL5/Hub1 in higher eukaryotes?

(8) At a molecular level, how is UBL5/Hub1—constitutively and/or stress-induciblyimplicated in metabolic processes and disorders as well as other diseases?

In conclusion, UBL5/Hub1 is an atypical member of the UBL family due to its distinct mode of function; nevertheless, the protein is typical in a sense because it is responsive to stresses and plays regulatory roles similar to many members of the family. If there is any interplay between UBL5/Hub1 and its relatives, it would be interesting to see what shall be written in the next chapter of UBL family history.

Funding: Research in my lab is supported by Mahidol University (Basic Research Fund, fiscal year 2021; Grant number IO863090089000) and the Research Grant for New Scholar from the Ministry of High Education, Science, Research and Innovation (RGNS 63-178).

Institutional Review Board Statement: Not applicable.

Informed Consent Statement: Not applicable.

Data Availability Statement: Data sharing not applicable.

Acknowledgments: This review article is dedicated to the memory of my great mentor and inspirational scientist Stefan Jentsch (1955-2016).

Conflicts of Interest: The author declares no conflict of interest.

\section{References}

1. Hochstrasser, M. Origin and Function of Ubiquitin-like Proteins. Nature 2009, 458, 422-429. [CrossRef] [PubMed]

2. Kerscher, O.; Felberbaum, R.; Hochstrasser, M. Modification of Proteins by Ubiquitin and Ubiquitin-Like Proteins. Annu. Rev. Cell Dev. Biol. 2006, 22, 159-180. [CrossRef] [PubMed]

3. Hochstrasser, M. Ubiquitin-Dependent Protein Degradation. Annu. Rev. Genet. 1996, 30, 405-439. [CrossRef] [PubMed]

4. Jentsch, S.; Pyrowolakis, G. Ubiquitin and Its Kin: How Close Are the Family Ties? Trends Cell Biol. 2000, 10, 335-342. [CrossRef]

5. Cappadocia, L.; Lima, C.D. Ubiquitin-like Protein Conjugation: Structures, Chemistry, and Mechanism. Chem. Rev. 2018, 118, 889-918. [CrossRef] [PubMed]

6. Crooks, G.E. WebLogo: A Sequence Logo Generator. Genome Res. 2004, 14, 1188-1190. [CrossRef] [PubMed]

7. Altschul, S.F.; Wootton, J.C.; Gertz, E.M.; Agarwala, R.; Morgulis, A.; Schaffer, A.A.; Yu, Y.-K. Protein Database Searches Using Compositionally Adjusted Substitution Matrices. FEBS J. 2005, 272, 5101-5109. [CrossRef] [PubMed]

8. Lüders, J.; Pyrowolakis, G.; Jentsch, S. The Ubiquitin-like Protein HUB1 Forms SDS-resistant Complexes with Cellular Proteins in the Absence of ATP. EMBO Rep. 2003, 4, 1169-1174. [CrossRef]

9. McNally, T.; Huang, Q.; Janis, R.S.; Liu, Z.; Olejniczak, E.T.; Reilly, R.M. Structural Analysis of UBL5, a Novel Ubiquitin-like Modifier. Protein Sci. 2003, 12, 1562-1566. [CrossRef]

10. Mishra, S.K.; Ammon, T.; Popowicz, G.M.; Krajewski, M.; Nagel, R.J.; Ares, M.; Holak, T.A.; Jentsch, S. Role of the Ubiquitin-like Protein Hub1 in Splice-Site Usage and Alternative Splicing. Nature 2011, 474, 173-178. [CrossRef]

11. Ammon, T.; Mishra, S.K.; Kowalska, K.; Popowicz, G.M.; Holak, T.A.; Jentsch, S. The Conserved Ubiquitin-like Protein Hub1 Plays a Critical Role in Splicing in Human Cells. J. Mol. Cell Biol. 2014, 6, 312-323. [CrossRef]

12. Ramelot, T.A.; Cort, J.R.; Yee, A.A.; Semesi, A.; Edwards, A.M.; Arrowsmith, C.H.; Kennedy, M.A. Solution Structure of the Yeast Ubiquitin-like Modifier Protein Hub1. J. Struct Func. Genom. 2003, 4, 25-30. [CrossRef]

13. Grabbe, C.; Dikic, I. Functional Roles of Ubiquitin-Like Domain (ULD) and Ubiquitin-Binding Domain (UBD) Containing Proteins. Chem. Rev. 2009, 109, 1481-1494. [CrossRef] 
14. Madsen, L.; Schulze, A.; Seeger, M.; Hartmann-Petersen, R. Ubiquitin Domain Proteins in Disease. BMC Biochem. 2007,8 , S1. [CrossRef] [PubMed]

15. Dittmar, G.A.G.; Wilkinson, C.R.M.; Jedrzejewski, P.T.; Finley, D. Role of a Ubiquitin-Like Modification in Polarized Morphogenesis. Science 2002, 295, 2442-2446. [CrossRef]

16. Laney, J.D.; Hochstrasser, M. Analysis of Protein Ubiquitination. Curr. Protoc. Protein Sci. 2011, 66. [CrossRef]

17. Yashiroda, H.; Tanaka, K. Hub1 Is an Essential Ubiquitin-like Protein without Functioning as a Typical Modifier in Fission Yeast: Role of Hub1 in S. Pombe. Genes Cells 2004, 9, 1189-1197. [CrossRef] [PubMed]

18. Hartmann-Petersen, R.; Gordon, C. Integral UBL Domain Proteins: A Family of Proteasome Interacting Proteins. Semin. Cell Dev. Biol. 2004, 15, 247-259. [CrossRef] [PubMed]

19. Will, C.L.; Luhrmann, R. Spliceosome Structure and Function. Cold Spring Harb. Perspect. Biol. 2011, 3, a003707. [CrossRef] [PubMed]

20. Wahl, M.C.; Will, C.L.; Lührmann, R. The Spliceosome: Design Principles of a Dynamic RNP Machine. Cell 2009, 136, 701-718. [CrossRef]

21. Faustino, N.A.; Cooper, T.A. Pre-MRNA Splicing and Human Disease. Genes Dev. 2003, 17, 419-437. [CrossRef] [PubMed]

22. Montes, M.; Sanford, B.L.; Comiskey, D.F.; Chandler, D.S. RNA Splicing and Disease: Animal Models to Therapies. Trends Genet. 2019, 35, 68-87. [CrossRef]

23. Cordin, O.; Beggs, J.D. RNA Helicases in Splicing. RNA Biol. 2013, 10, 83-95. [CrossRef] [PubMed]

24. Cordin, O.; Hahn, D.; Beggs, J.D. Structure, Function and Regulation of Spliceosomal RNA Helicases. Curr. Opin. Cell Biol. 2012, 24, 431-438. [CrossRef] [PubMed]

25. Liang, W.-W.; Cheng, S.-C. A Novel Mechanism for Prp5 Function in Prespliceosome Formation and Proofreading the Branch Site Sequence. Genes Dev. 2015, 29, 81-93. [CrossRef] [PubMed]

26. Egecioglu, D.E.; Chanfreau, G. Proofreading and Spellchecking: A Two-Tier Strategy for Pre-MRNA Splicing Quality Control. RNA 2011, 17, 383-389. [CrossRef]

27. Karaduman, R.; Chanarat, S.; Pfander, B.; Jentsch, S. Error-Prone Splicing Controlled by the Ubiquitin Relative Hub1. Mol. Cell 2017, 67, 423.e4-432.e4. [CrossRef]

28. Watanabe, E.; Mano, S.; Nishimura, M.; Yamada, K. AtUBL5 Regulates Growth and Development through Pre-MRNA Splicing in Arabidopsis Thaliana. PLoS ONE 2019, 14, e224795. [CrossRef]

29. Nguyen, T.H.D.; Galej, W.P.; Bai, X.; Oubridge, C.; Newman, A.J.; Scheres, S.H.W.; Nagai, K. Cryo-EM Structure of the Yeast U4/U6.U5 Tri-SnRNP at $3.7 \AA$ Resolution. Nature 2016, 530, 298-302. [CrossRef]

30. Townsend, C.; Leelaram, M.N.; Agafonov, D.E.; Dybkov, O.; Will, C.L.; Bertram, K.; Urlaub, H.; Kastner, B.; Stark, H.; Lührmann, R. Mechanism of Protein-Guided Folding of the Active Site U2/U6 RNA during Spliceosome Activation. Science 2020, eabc3753. [CrossRef]

31. Zhan, X.; Yan, C.; Zhang, X.; Lei, J.; Shi, Y. Structures of the Human Pre-Catalytic Spliceosome and Its Precursor Spliceosome. Cell Res. 2018, 28, 1129-1140. [CrossRef] [PubMed]

32. Yildirim, A.; Mozaffari-Jovin, S.; Wallisch, A.-K.; Schäfer, J.; Ludwig, S.E.J.; Urlaub, H.; Lührmann, R.; Wolfrum, U. SANS (USH1G) Regulates Pre-MRNA Splicing by Mediating the Intra-Nuclear Transfer of Tri-SnRNP Complexes. Nucleic Acids Res. 2021, 49, 5845-5866. [CrossRef] [PubMed]

33. Švéda, M.; Častorálová, M.; Lipov, J.; Ruml, T.; Knejzlík, Z. Human UBL5 Protein Interacts with Coilin and Meets the Cajal Bodies. Biochem. Biophys. Res. Commun. 2013, 436, 240-245. [CrossRef]

34. Rode, S.; Ohm, H.; Zipfel, J.; Rumpf, S. The Spliceosome-Associated Protein Mfap1 Binds to VCP in Drosophila. PLoS ONE 2017, 12, e0183733. [CrossRef]

35. Staněk, D. Cajal Bodies and SnRNPs—Friends with Benefits. RNA Biol. 2017, 14, 671-679. [CrossRef]

36. Sawyer, I.A.; Sturgill, D.; Sung, M.-H.; Hager, G.L.; Dundr, M. Cajal Body Function in Genome Organization and Transcriptome Diversity. BioEssays 2016, 38, 1197-1208. [CrossRef]

37. Xu, Y.-Z.; Newnham, C.M.; Kameoka, S.; Huang, T.; Konarska, M.M.; Query, C.C. Prp5 Bridges U1 and U2 SnRNPs and Enables Stable U2 SnRNP Association with Intron RNA. EMBO J. 2004, 23, 376-385. [CrossRef] [PubMed]

38. Xu, Y.-Z.; Query, C.C. Competition between the ATPase Prp5 and Branch Region-U2 SnRNA Pairing Modulates the Fidelity of Spliceosome Assembly. Mol. Cell 2007, 28, 838-849. [CrossRef]

39. Chanarat, S.; Svasti, J. Stress-Induced Upregulation of the Ubiquitin-Relative Hub1 Modulates Pre-MRNA Splicing and Facilitates Cadmium Tolerance in Saccharomyces Cerevisiae. Biochim. Biophys. Acta Mol. Cell Res. 2020, 1867, 118565. [CrossRef]

40. Patel, M.; Milla-Lewis, S.; Zhang, W.; Templeton, K.; Reynolds, W.C.; Richardson, K.; Biswas, M.; Zuleta, M.C.; Dewey, R.E.; Qu, R.; et al. Overexpression of Ubiquitin-like LpHUB1 Gene Confers Drought Tolerance in Perennial Ryegrass. Plant. Biotechnol. J. 2015, 13, 689-699. [CrossRef] [PubMed]

41. Hatanaka, K.; Ikegami, K.; Takagi, H.; Setou, M. Hypo-Osmotic Shock Induces Nuclear Export and Proteasome-Dependent Decrease of UBL5. Biochem. Biophys. Res. Commun. 2006, 350, 610-615. [CrossRef] [PubMed]

42. Chanarat, S.; Mishra, S.K. Emerging Roles of Ubiquitin-like Proteins in Pre-MRNA Splicing. Trends Biochem. Sci. 2018, 43, 896-907. [CrossRef]

43. Capella, M.; Caballero, L.M.; Pfander, B.; Braun, S.; Jentsch, S. ESCRT Recruitment by the Inner Nuclear Membrane Protein Heh1 Is Regulated by Hub1-Mediated Alternative Splicing. J. Cell Sci. 2020, jcs.250688. [CrossRef] [PubMed] 
44. Grund, S.E.; Fischer, T.; Cabal, G.G.; Antúnez, O.; Pérez-Ortín, J.E.; Hurt, E. The Inner Nuclear Membrane Protein Src1 Associates with Subtelomeric Genes and Alters Their Regulated Gene Expression. J. Cell Biol. 2008, 182, 897-910. [CrossRef] [PubMed]

45. Oka, Y.; Varmark, H.; Vitting-Seerup, K.; Beli, P.; Waage, J.; Hakobyan, A.; Mistrik, M.; Choudhary, C.; Rohde, M.; Bekker-Jensen, S.; et al. UBL5 Is Essential for Pre-mRNA Splicing and Sister Chromatid Cohesion in Human Cells. EMBO Rep. 2014, 15, 956-964. [CrossRef] [PubMed]

46. Mishra, S.K.; Thakran, P. Intron Specificity in Pre-MRNA Splicing. Curr Genet. 2018, 64, 777-784. [CrossRef] [PubMed]

47. Da Costa, I.C.; Schmidt, C.K. Ubiquitin-like Proteins in the DNA Damage Response: The next Generation. Essays Biochem. 2020, 64, 737-752. [CrossRef]

48. Kantham, L.; Kerr-Bayles, L.; Godde, N.; Quick, M.; Webb, R.; Sunderland, T.; Bond, J.; Walder, K.; Augert, G.; Collier, G. Beacon Interacts with Cdc2/Cdc28-like Kinases. Biochem. Biophys. Res. Commun. 2003, 304, 125-129. [CrossRef]

49. Zhou, Z.; Fu, X.-D. Regulation of Splicing by SR Proteins and SR Protein-Specific Kinases. Chromosoma 2013, 122, 191-207. [CrossRef]

50. Xiang, S.; Gapsys, V.; Kim, H.-Y.; Bessonov, S.; Hsiao, H.-H.; Möhlmann, S.; Klaukien, V.; Ficner, R.; Becker, S.; Urlaub, H.; et al. Phosphorylation Drives a Dynamic Switch in Serine/Arginine-Rich Proteins. Structure 2013, 21, 2162-2174. [CrossRef]

51. Zheng, X.; Peng, Q.; Wang, L.; Zhang, X.; Huang, L.; Wang, J.; Qin, Z. Serine/Arginine-Rich Splicing Factors: The Bridge Linking Alternative Splicing and Cancer. Int. J. Biol. Sci. 2020, 16, 2442-2453. [CrossRef]

52. Mermoud, J.E.; Cohen, P.; Lamond, A.I. Ser/Thr-Specific Protein Phosphatases Are Required for Both Catalytic Steps of Pre-MRNA Splicing. Nucl Acids Res. 1992, 20, 5263-5269. [CrossRef]

53. Mermoud, J.E.; Cohen, P.T.; Lamond, A.I. Regulation of Mammalian Spliceosome Assembly by a Protein Phosphorylation Mechanism. EMBO J. 1994, 13, 5679-5688. [CrossRef]

54. Huang, Y.; Gattoni, R.; Stévenin, J.; Steitz, J.A. SR Splicing Factors Serve as Adapter Proteins for TAP-Dependent MRNA Export. Mol. Cell 2003, 11, 837-843. [CrossRef]

55. Lai, M.-C.; Tarn, W.-Y. Hypophosphorylated ASF/SF2 Binds TAP and Is Present in Messenger Ribonucleoproteins. J. Biol. Chem. 2004, 279, 31745-31749. [CrossRef]

56. Prasad, J.; Manley, J.L. Regulation and Substrate Specificity of the SR Protein Kinase Clk/Sty. Mol. Cell Biol. 2003, 23, 4139-4149. [CrossRef]

57. Ben-David, Y.; Letwin, K.; Tannock, L.; Bernstein, A.; Pawson, T. A Mammalian Protein Kinase with Potential for Serine/Threonine and Tyrosine Phosphorylation Is Related to Cell Cycle Regulators. EMBO J. 1991, 10, 317-325. [CrossRef]

58. Nayler, O.; Stamm, S.; Ullrich, A. Characterization and Comparison of Four Serine- and Arginine-Rich (SR) Protein Kinases. Biochem. J. 1997, 326, 693-700. [CrossRef]

59. Tim, A. Characterization of the Ubiquitin-like Protein Hub1 and Its Role in Pre-MRNA Splicing in Human Cells. Ph.D. Thesis, Ludwig-Maximilians-Universität München, München, Germany, 2013.

60. Oka, Y.; Bekker-Jensen, S.; Mailand, N. Ubiquitin-like Protein UBL5 Promotes the Functional Integrity of the Fanconi Anemia Pathway. EMBO J. 2015, 34, 1385-1398. [CrossRef]

61. Fernandes, P.; Miotto, B.; Saint-Ruf, C.; Said, M.; Barra, V.; Nähse, V.; Ravera, S.; Cappelli, E.; Naim, V. FANCD2 Modulates the Mitochondrial Stress Response to Prevent Common Fragile Site Instability. Commun. Biol. 2021, 4, 127. [CrossRef]

62. Ceccaldi, R.; Sarangi, P.; D’Andrea, A.D. The Fanconi Anaemia Pathway: New Players and New Functions. Nat. Rev. Mol. Cell Biol 2016, 17, 337-349. [CrossRef]

63. Rodríguez, A.; D'Andrea, A. Fanconi Anemia Pathway. Curr. Biol. 2017, 27, R986-R988. [CrossRef]

64. Meng, X.; Yang, S.; Camp, V.J.A. The Interplay Between the DNA Damage Response, RNA Processing and Extracellular Vesicles. Front. Oncol. 2020, 9. [CrossRef] [PubMed]

65. Mikolaskova, B.; Jurcik, M.; Cipakova, I.; Kretova, M.; Chovanec, M.; Cipak, L. Maintenance of Genome Stability: The Unifying Role of Interconnections between the DNA Damage Response and RNA-Processing Pathways. Curr. Genet. 2018, 64, 971-983. [CrossRef]

66. Chanarat, S.; Sträßer, K. Splicing and beyond: The Many Faces of the Prp19 Complex. Biochim. Biophys. Acta Mol. Cell Res. 2013, 1833, 2126-2134. [CrossRef]

67. Shkreta, L.; Chabot, B. The RNA Splicing Response to DNA Damage. Biomolecules 2015, 5, 2935-2977. [CrossRef]

68. Lenzken, S.C.; Loffreda, A.; Barabino, S.M.L. RNA Splicing: A New Player in the DNA Damage Response. Int. J. Cell Biol. 2013, 2013, 153634 . [CrossRef]

69. Chanarat, S.; Seizl, M.; Sträßer, K. The Prp19 Complex Is a Novel Transcription Elongation Factor Required for TREX Occupancy at Transcribed Genes. Genes Dev. 2011, 25, 1147-1158. [CrossRef] [PubMed]

70. Moriel-Carretero, M.; Ovejero, S.; Gérus-Durand, M.; Vryzas, D.; Constantinou, A. Fanconi Anemia FANCD2 and FANCI Proteins Regulate the Nuclear Dynamics of Splicing Factors. J. Cell Biol. 2017, 216, 4007-4026. [CrossRef] [PubMed]

71. Quesada, V.; Conde, L.; Villamor, N.; Ordóñez, G.R.; Jares, P.; Bassaganyas, L.; Ramsay, A.J.; Beà, S.; Pinyol, M.; Martínez-Trillos, A.; et al. Exome Sequencing Identifies Recurrent Mutations of the Splicing Factor SF3B1 Gene in Chronic Lymphocytic Leukemia. Nat. Genet. 2012, 44, 47-52. [CrossRef]

72. Wang, L.; Lawrence, M.S.; Wan, Y.; Stojanov, P.; Sougnez, C.; Stevenson, K.; Werner, L.; Sivachenko, A.; DeLuca, D.S.; Zhang, L.; et al. SF3B1 and Other Novel Cancer Genes in Chronic Lymphocytic Leukemia. N. Engl. J. Med. 2011, 365, 2497-2506. [CrossRef] [PubMed] 
73. Tanikawa, M.; Sanjiv, K.; Helleday, T.; Herr, P.; Mortusewicz, O. The Spliceosome U2 SnRNP Factors Promote Genome Stability through Distinct Mechanisms; Transcription of Repair Factors and R-Loop Processing. Oncogenesis 2016, 5, e280. [CrossRef]

74. Hartl, F.; Neupert, W. Protein Sorting to Mitochondria: Evolutionary Conservations of Folding and Assembly. Science 1990, 247, 930-938. [CrossRef] [PubMed]

75. Benedetti, C.; Haynes, C.M.; Yang, Y.; Harding, H.P.; Ron, D. Ubiquitin-Like Protein 5 Positively Regulates Chaperone Gene Expression in the Mitochondrial Unfolded Protein Response. Genetics 2006, 174, 229-239. [CrossRef]

76. Haynes, C.M.; Petrova, K.; Benedetti, C.; Yang, Y.; Ron, D. ClpP Mediates Activation of a Mitochondrial Unfolded Protein Response in C. Elegans. Dev. Cell 2007, 13, 467-480. [CrossRef]

77. Liu, H.; Wang, D. Intestinal Mitochondrial Unfolded Protein Response Induced by Nanoplastic Particles in Caenorhabditis Elegans. Chemosphere 2021, 267, 128917. [CrossRef]

78. Collier, G.R.; McMillan, J.S.; Windmill, K.; Walder, K.; Tenne-Brown, J.; de Silva, A.; Trevaskis, J.; Jones, S.; Morton, G.J.; Lee, S.; et al. Beacon: A Novel Gene Involved in the Regulation of Energy Balance. Diabetes 2000, 49, 1766-1771. [CrossRef] [PubMed]

79. Walder, K.; Ziv, E.; Kalman, R.; Whitecross, K.; Shafrir, E.; Zimmet, P.; Collier, G.R. Elevated Hypothalamic Beacon Gene Expression in Psammomys Obesus Prone to Develop Obesity and Type 2 Diabetes. Int. J. Obes. Relat. Metab. Disord. 2002, 26, 605-609. [CrossRef]

80. Dashti, H.S.; Jones, S.E.; Wood, A.R.; Lane, J.M.; van Hees, V.T.; Wang, H.; Rhodes, J.A.; Song, Y.; Patel, K.; Anderson, S.G.; et al. Genome-Wide Association Study Identifies Genetic Loci for Self-Reported Habitual Sleep Duration Supported by AccelerometerDerived Estimates. Nat. Commun. 2019, 10, 1100. [CrossRef]

81. Cesar, A.S.M.; Regitano, L.C.A.; Koltes, J.E.; Fritz-Waters, E.R.; Lanna, D.P.D.; Gasparin, G.; Mourão, G.B.; Oliveira, P.S.N.; Reecy, J.M.; Coutinho, L.L. Putative Regulatory Factors Associated with Intramuscular Fat Content. PLoS ONE 2015, 10, e0128350. [CrossRef]

82. Cepica, S.; Ovilo, C.; Masopust, M.; Knoll, A.; Fernandez, A.; Lopez, A.; Rohrer, G.A.; Nonneman, D. Four Genes Located on a SSC2 Meat Quality QTL Region Are Associated with Different Meat Quality Traits in Landrace $\times$ Chinese-European Crossbred Population. Anim Genet. 2012, 43, 333-336. [CrossRef]

83. Bozaoglu, K.; Curran, J.E.; Elliott, K.S.; Walder, K.R.; Dyer, T.D.; Rainwater, D.L.; VandeBerg, J.L.; Comuzzie, A.G.; Collier, G.R.; Zimmet, P.; et al. Association of Genetic Variation within UBL5 with Phenotypes of Metabolic Syndrome. Hum. Biol. 2006, 78, 147-159. [CrossRef]

84. Jowett, J.B.; Elliott, K.S.; Curran, J.E.; Hunt, N.; Walder, K.R.; Collier, G.R.; Zimmet, P.Z.; Blangero, J. Genetic Variation in BEACON Influences Quantitative Variation in Metabolic Syndrome-Related Phenotypes. Diabetes 2004, 53, 2467-2472. [CrossRef] [PubMed]

85. Wang, F.; Tian, D.-R.; Tian, N.; Chen, H.; Shi, Y.-S.; Chang, J.-K.; Yang, J.; Yuan, L.; Han, J.-S. Distribution of Beacon Immunoreactivity in the Rat Brain. Peptides 2006, 27, 165-171. [CrossRef] [PubMed]

86. Nowak, K.W.; Ruciński, M.; Kaczmarek, P.; Szkudelski, T.; Malendowicz, L.K. Expression of the Beacon Gene in the Rat Pancreatic Islets: Opposite Effects of Beacon (47-73) Protein (Ubiquitin-like Protein 5) on Insulin Secretion in Vivo and Insulin Release by Isolated Islets. Pancreas 2004, 29, 99-103. [CrossRef] [PubMed]

87. Rucinski, M.; Spinazzi, R.; Ziolkowska, A.; Nussdorfer, G.G.; Malendowicz, L.K. Effects of Beacon on the Rat PituitaryAdrenocortical Axis Response to Stress. Int. J. Mol. Med. 2005, 16, 297-299. [CrossRef] [PubMed]

88. Ziolkowska, A.; Rucinski, M.; Di Liddo, R.; Nussdorfer, G.G.; Malendowicz, L.K. Expression of the Beacon Gene in Endocrine Glands of the Rat. Peptides 2004, 25, 133-137. [CrossRef]

89. Brailoiu, G.C.; Dun, S.L.; Chi, M.; Ohsawa, M.; Chang, J.K.; Yang, J.; Dun, N.J. Beacon/Ubiquitin-like 5-Immunoreactivity in the Hypothalamus and Pituitary of the Mouse. Brain Res. 2003, 984, 215-223. [CrossRef]

90. Bernstein, H.-G.; Lendeckel, U.; Dobrowolny, H.; Stauch, R.; Steiner, J.; Grecksch, G.; Becker, A.; Jirikowski, G.F.; Bogerts, B. Beacon-like/Ubiquitin-5-like Immunoreactivity Is Highly Expressed in Human Hypothalamus and Increased in HaloperidolTreated Schizophrenics and a Rat Model of Schizophrenia. Psychoneuroendocrinology 2008, 33, 340-351. [CrossRef]

91. Ng, Y.K.; Brailoiu, G.C.; Dun, S.L.; Ling, E.A.; Yang, J.; Chang, J.K.; Dun, N.J. Beacon Immunoreactivity in the Rat Hypothalamus. J. Neurosci. Res. 2006, 83, 1106-1117. [CrossRef] 